
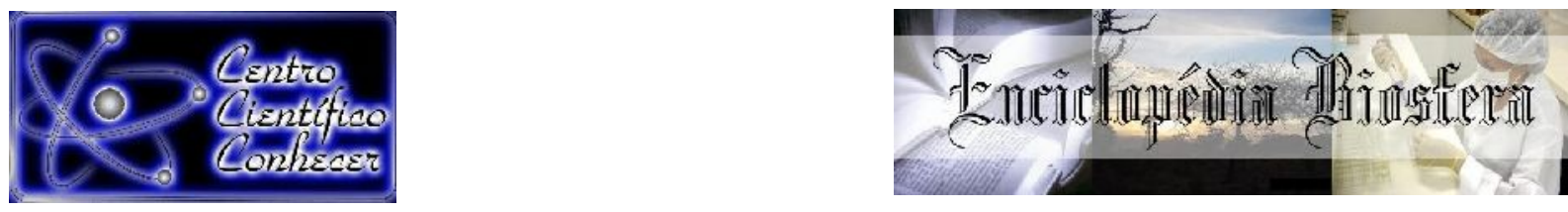

\title{
UTILIZAÇÃO DE RESÍDUO INDUSTRIAL PARA PRODUÇÃO DE MUDAS DE JATOBÁ-DA-MATA (Hymenaea courbaril L.)
}

Christiane Ribeiro do Amaral ${ }^{1}$, Jaqueline Pinheiro da Silva², Jhonatan Willian Moreira ${ }^{3}$, Sybelle Barreira ${ }^{4}$

${ }^{1}$ Bacharel em Engenharia Florestal pela Universidade Federal de Goiás (UFG), Goiânia-GO, Brasil.

${ }^{2}$ Doutoranda em Agronegócio na Universidade Federal de Goiás (UFG), Goiânia-GO,

Brasil. E-mail: jaquelinepinheiro@discente.ufg.br

${ }^{3}$ Graduando em Engenharia Florestal na Universidade Federal de Goiás (UFG), Goiânia-GO, Brasil.

${ }^{4}$ Professora Doutora da Escola de Agronomia, departamento de Engenharia Florestal, da Universidade Federal de Goiás, Goiânia-GO, Brasil.

Recebido em: 15/11/2020 - Aprovado em: 15/12/2020 - Publicado em: 30/12/2020

DOI: 10.18677/EnciBio_2020D41

\begin{abstract}
RESUMO
O jatobá-da-mata (Hymenaea courbaril L.) é uma espécie florestal que possui madeira de qualidade, recomendada na recuperação de áreas degradadas. Pouco se conhece a respeito de seu comportamento, propagado em diferentes substratos. Portanto, a presente pesquisa teve o objetivo de avaliar a utilização de um resíduo proveniente de atividade industrial de casca de batata (Solanum tuberosum L.), na produção de mudas do jatobá-da-mata, para assim, indicar um substrato viável tecnicamente e economicamente para produção de mudas florestais. O composto orgânico utilizado no experimento é proveniente de cascas de batata cedido pela indústria alimentícia CICOPAL. O experimento foi conduzido em três tratamentos, com 4 repetições, utilizando o resíduo compostado: tratamento 1 (100\% composto orgânico de casca de batata), tratamento 2 (50\% composto orgânico de casca de batata $+50 \%$ areia), tratamento 3 (100\% areia). Foram analisadas: altura, diâmetro de coleto, peso verde da parte aérea, peso verde do sistema radicular, peso seco da parte aérea e peso seco do sistema radicular, até os 54 dias após a germinação das sementes de jatobá, visando identificar as melhores condições de qualidade das mudas nos diferentes tratamentos. As sementes de jatobá-da-mata apresentaram, em laboratório, germinação de $91 \%$. No viveiro, foram obtidos $83 \%, 81 \%$ e $90 \%$, respectivamente, nos tratamentos T1, T2 e T3, indicando que as mudas tiveram alta taxa de germinação. O teste de Tukey a $5 \%$ de probabilidade, não apresentou diferença estatística significativa, logo, os viveiros podem optar por alternativas menos onerosas.
\end{abstract}

PALAVRAS-CHAVE: Composto orgânico; Cerrado, Resíduos. 


\title{
USE OF INDUSTRIAL WASTE FOR PRODUCTION OF JATOBÁ-DA-MATA SEEDLINGS (Hymenaea courbaril L.)
}

\begin{abstract}
The jatobá-da-mata (Hymenaea courbaril L.) is a forest species that has quality wood, recommended in the recovery of degraded areas. Little is known about its behavior, propagated on different substrates. Therefore, the present research had the objective of evaluating the use of a residue from potato peel industrial activity (Solanum tuberosum L.), in the production of jatobá-da-mata seedlings, in order to indicate a technically viable substrate and economically for the production of forest seedlings. The organic compound used in the experiment comes from potato skins provided by the food industry CICOPAL. The experiment was conducted in three treatments, with 4 repetitions, using the composted residue: treatment 1 (100\% potato peel organic compound), treatment 2 (50\% potato peel organic compound $+50 \%$ sand), treatment 3 (100\% sand). Height, stem diameter, green weight of the aerial part, green weight of the root system, dry weight of the aerial part and dry weight of the root system were analyzed, up to 54 days after the germination of the jatobá seeds, in order to identify the best conditions for quality of seedlings in different treatments. The seeds of jatobá-damata showed $91 \%$ germination in the laboratory. In the nursery, $83 \%, 81 \%$ and $90 \%$ were obtained, respectively, in treatments T1, T2 and T3, indicating that the seedlings had a high germination rate. Tukey's test at $5 \%$ probability did not show a statistically significant difference, so nurseries can choose less expensive alternatives.
\end{abstract}

KEYWORDS: Waste; Organic compost; Cerrado.

\section{INTRODUÇÃO}

As altas taxas de consumo no Brasil e a crescente produção de resíduos, estão entre os maiores problemas ambientais enfrentados devido à expansão e o adensamento dos aglomerados urbanos, já que a infraestrutura sanitária da maioria das cidades brasileiras não acompanha o ritmo acelerado desse crescimento. Com o aumento da produção das indústrias de alimentos, verifica-se o aumento da geração de resíduos e diversos estudos em todo o mundo estão sendo realizados a fim de criar soluções para diminuir ou eliminar os passivos ambientais gerados pelas agroindústrias de alimentos. Esses resíduos possuem em sua composição vitaminas, minerais, fibras e compostos antioxidantes importantes para as funções fisiológicas (BARBOSA; CONCEIÇÃO, 2016).

Várias indústrias geram quantidades significativas de resíduos que prejudicam o meio ambiente, tais como indústria têxtil, de borracha, papel, plásticos, couro, cosméticos, farmacêutica e, principalmente, a de alimentos. A crescente preocupação com o meio ambiente abrange todos os segmentos industriais na busca de alternativas para o correto aproveitamento dos rejeitos (BARBOSA; CONCEIÇÃO, 2016).

Sabe-se que os resíduos sólidos urbanos são compostos, em sua grande parte por matéria orgânica e por materiais recicláveis, revelando não só a necessidade de minimização na geração, mas também a potencialidade da reciclagem de materiais, como o metal, papel, papelão, a embalagem tetra pak, o plástico e vidro (ZARO, 2018).

Assim, adições de resíduos compostados em solos provocam benefícios para a nutrição das plantas e a utilização agronômica pressupõe diversidade de aplicações, 
entre as quais pode-se lembrar a utilização em alimentação animal, substrato para fermentações, fabricação de fertilizantes orgânicos, em fins energéticos e agronômicos, pois é rico em matéria orgânica, nutrientes, e se mostra importante para as propriedades físicas e químicas do solo e deve ser aproveitado nas mais diversas formas possíveis (BETTIOL; CAMARGO, 2000).

O jatobá é uma árvore de grande porte, podendo atingir de 30 a 40 metros de altura, possui tronco reto, podendo atingir dois metros de diâmetro e a casca é grossa com até três centímetros (LORENZI, 2016). A espécie Hymenaea courbaril L. é citada como sendo uma árvore recomendada para uso em áreas de restauração florestal no caso de reserva legal e áreas de preservação permanente, sendo uma espécie não pioneira e com frutos atrativos para a fauna (MARTINS, 2013).

A espécie Hymenaea courbaril L. possui grande importância socioambiental, é utilizada amplamente em áreas degradadas destinadas à recomposição vegetal. Segundo Lorenzi (2016), a madeira é pesada, com densidade de 0,96 g cm possível ser utilizada na construção civil, como vigas, caibros, acabamentos internos, assoalho, além de ser utilizada em artigos esportivos, cabos de ferramentas, peças torneadas, esquadrias e móveis, caracterizando-a com isso em espécie de interesse econômico.

A identificação e utilização de substratos menos onerosos e que se mostrem adequados para a produção de mudas, possibilita aos viveiristas possibilidade de melhor planejamento da atividade, bem como aumento na possibilidade de produzir mudas sadias e vigorosas, contribuindo para a preservação e propagação das espécies. Assim, a produção de mudas nativas com qualidade deve estar relacionada com meios sustentáveis de produção através do uso de composto orgânico proveniente de resíduos industriais, que contribui para o aproveitamento e evita o descarte inadequado destes resíduos, barateando os custos de produção e faz com que viveiros se tornem um negócio mais acessível a todos os produtores rurais, interessados em recompor suas áreas ou explorar alguma atividade silvicultural, trazendo vários benefícios, não só monetários, como também a melhoria da qualidade ambiental (LORENZI, 2016).

Desta forma, considerando a importância da utilização de um resíduo industrial, que pode se tornar problema ambiental, como substrato para a produção de mudas florestais, o presente estudo teve como objetivo utilizar resíduo proveniente de atividade industrial de casca de batata (Solanum tuberosum L.) na produção de mudas do jatobá-da-mata para assim, indicar um substrato viável tecnicamente e economicamente para produção de mudas florestais.

\section{MATERIAL E MÉTODOS}

O estudo foi realizado no Laboratório de Reprodução de Espécies Florestais (REFLOR) no Campus Samambaia da Universidade Federal de Goiás (UFG), localizado no município de Goiânia, GO. No local do estudo predomina o clima tropical com estação seca Aw (KÖPPEN-GEIGER, 2020). A área tem como característica uma estação chuvosa de outubro a abril, e outra seca, de maio a setembro. O índice pluviométrico anual é de aproximadamente $1.570(\mathrm{~mm})$ e temperatura média de 23,2 ${ }^{\circ} \mathrm{C}$ com média mínima de $18{ }^{\circ} \mathrm{C}$ e a máxima de $30^{\circ} \mathrm{C}$ (normal climatológica de 1961 1990). 
A areia utilizada neste trabalho é proveniente do próprio Centro de Pesquisas da UFG e o composto orgânico utilizado no experimento é proveniente de cascas de batata, e foi cedido pela indústria alimentícia CICOPAL, localizada no município de Senador Canedo, Goiás. Os resíduos mais comuns oriundos do processamento de matérias-primas na empresa são pedaços de batata (in natura), restos de batata e salgadinhos fora do padrão de qualidade para a comercialização. Sendo os restos de batata e salgadinhos fora do padrão separados e doados à produtores da região para enriquecimento da ração animal. Já os resíduos industriais in natura, como as cascas e pedaços de batata, recebem tratamento, destinados a compostagem.

A espécie utilizada foi o jatobá-da-mata (Hymenaea courbaril L.), as sementes foram coletadas de uma matriz adulta localizada no município de Goiânia-GO, armazenadas em bandejas e mantidas em condições ambientais normais no Laboratório de Reprodução de Espécies Florestais (UFG) até o momento da utilização.

Para verificar a germinação das sementes de $H$. courbaril L. foram utilizadas 100 sementes, escarificadas em esmeril para facilitar e permitir a embebição, e separadas em quatro repetições de 25 sementes, colocadas em rolos de papel filtro, que foram esterilizados e umedecidos com água destilada para promover o processo de embebição das sementes, sendo colocadas em estufa modelo (Mangelsdorf) a temperatura constante de $30^{\circ} \mathrm{C}$ durante todo o período experimental. Foram consideradas como germinadas as sementes que apresentaram protrusão da radícula.

Foram utilizados três tratamentos com diferentes composições de substrato determinados a partir da combinação de areia proveniente do próprio Centro de Pesquisas da UFG, e composto orgânico de cascas de batata, cedido pela indústria alimentícia CICOPAL, localizada no município de Senador Canedo, Goiás (quadro 1).

QUADRO 1. Composição dos substratos utilizados no experimento para avaliar o desenvolvimento inicial de mudas de jatobá-da-mata (Hymenaea courbaril L.).

\begin{tabular}{|c|c|}
\hline Tratamentos & Composição \\
\hline T1 & $\begin{array}{r}\text { 100\% Composto Orgânico de Casca de } \\
\text { Batata (COCB) }\end{array}$ \\
\hline T2 & $\begin{array}{c}50 \% \text { Composto Orgânico de Casca de Batata }+50 \% \\
\text { Areia (COCB + A) }\end{array}$ \\
\hline T3 & $100 \%$ Areia (A) \\
\hline
\end{tabular}

As sementes passaram por escarificação mecânica em esmeril (Figura 1-A), e logo após foram desinfetadas com hipoclorito de sódio a $2,5 \%$ para eliminar microrganismos indesejáveis (Figura 1-B), antes de serem semeadas, uma em cada tubete, manualmente (Figura 1-C), de acordo com os tratamentos acima descritos. As mudas foram produzidas em tubetes cônicos de polipropileno, com volume de $180 \mathrm{~cm}^{3}$. 
FIGURA 1. Procedimentos na semeadura de sementes de jatobá-da-mata (Hymenaea courbaril L.). A) - Escarificação mecânica das sementes em esmeril. B) - Desinfecção de sementes em hipoclorito de sódio a 2,5\%. C - Distribuição das sementes em tubetes.

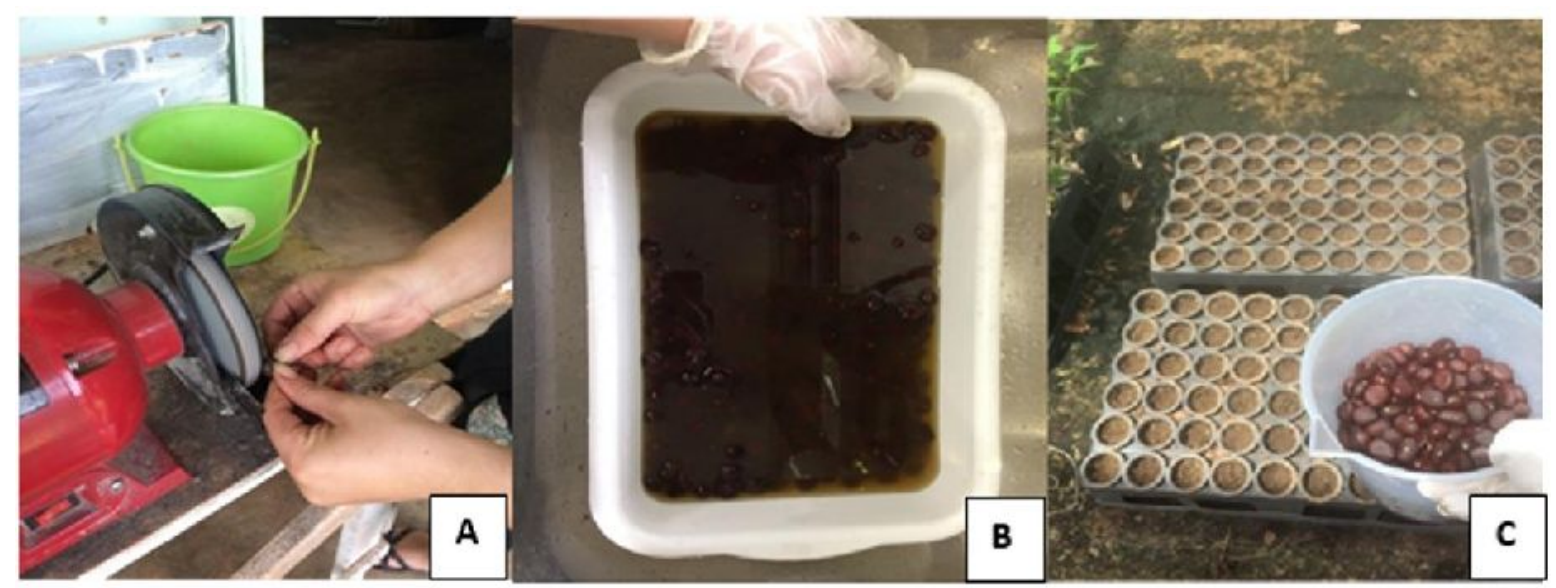

Fonte: Christiane Amaral (2020)

$O$ viveiro onde o experimento foi instalado possui ambiente telado com sombreamento $50 \%$, para obtenção de mudas isentas de doenças e pragas, com controle de irrigação que contribui para o fornecimento de nutrientes que está intimamente ligado à quantidade de água fornecida (Figura 2).

FIGURA 2. Experimento com jatobá-da-mata (Hymenea coubaril L.), em ambiente telado e com controle de irrigação, na Escola de Agronomia da Universidade Federal de Goiás. Goiânia-GO.

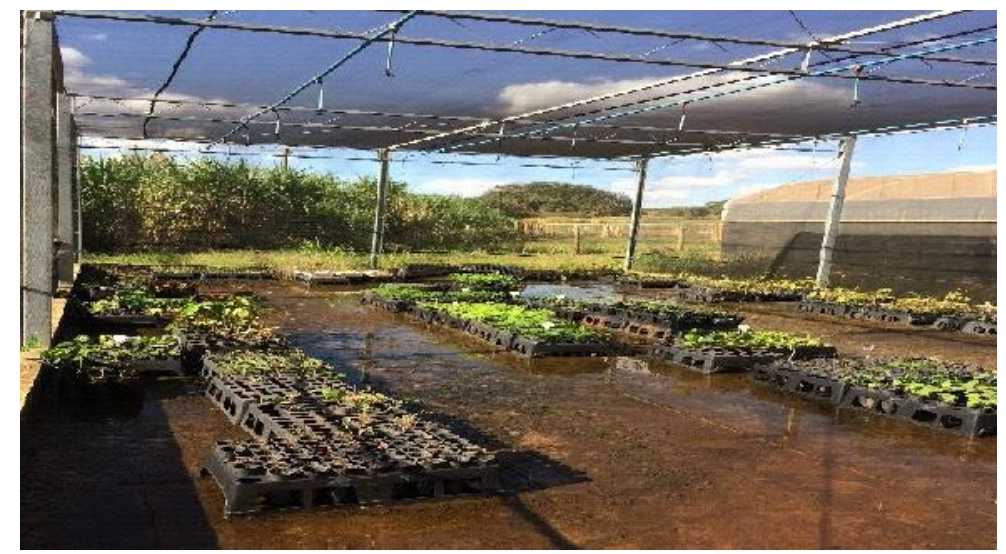

Fonte: Christiane Amaral (2020)

O delineamento experimental utilizado foi inteiramente casualizado, sendo constituído por três tratamentos com quatro repetições. Em cada repetição foram avaliadas as médias de 20 plântulas, através de amostragem aleatória. 
A avaliação iniciou-se desde a semeadura das sementes, no dia 21 de março de 2017, até a germinação completa destas. Após o período de germinação, a cada sete dias foram avaliadas as seguintes variáveis: até o dia 26 de maio de 2017: a) altura da parte aérea $(\mathrm{H})$, determinada a partir do nível do substrato até a inserção da última folha, com auxílio de uma régua e uma trena (Figura 3 - A); b) diâmetro do coleto (DC) mensurado na planta, no nível do substrato, com uso de um paquímetro digital (Figura 3 - B), totalizando oito avaliações de altura e diâmetro; c) o peso verde da parte aérea (PVPA) e o peso verde do sistema radicular (PVSR) (Figura 3 - C), e d) o peso seco da parte aérea (PSPA) e peso seco do sistema radicular (PSSR) (Figura 3 - D), ambos foram aferidos a partir do dia 02 de maio de 2017, sendo retiradas 10 plântulas de cada tratamento, através de amostragem aleatória, a cada semana, até o último dia de avaliação do experimento, totalizando quatro avaliações, sendo este material seco em estufa, permanecendo a $60{ }^{\circ} \mathrm{C}$ até atingir peso constante, posteriormente foi aferido 0 peso em balança graduada a $0,1 \mathrm{~g}$.

FIGURA 3. Avaliação do desenvolvimento inicial de jatobá-da-mata (Hymenaea courbaril L.). A - altura. B - diâmetro do coleto. C - peso verde da parte aérea e peso verde do sistema radicular. D - peso seco da parte aérea e peso seco do sistema radicular.

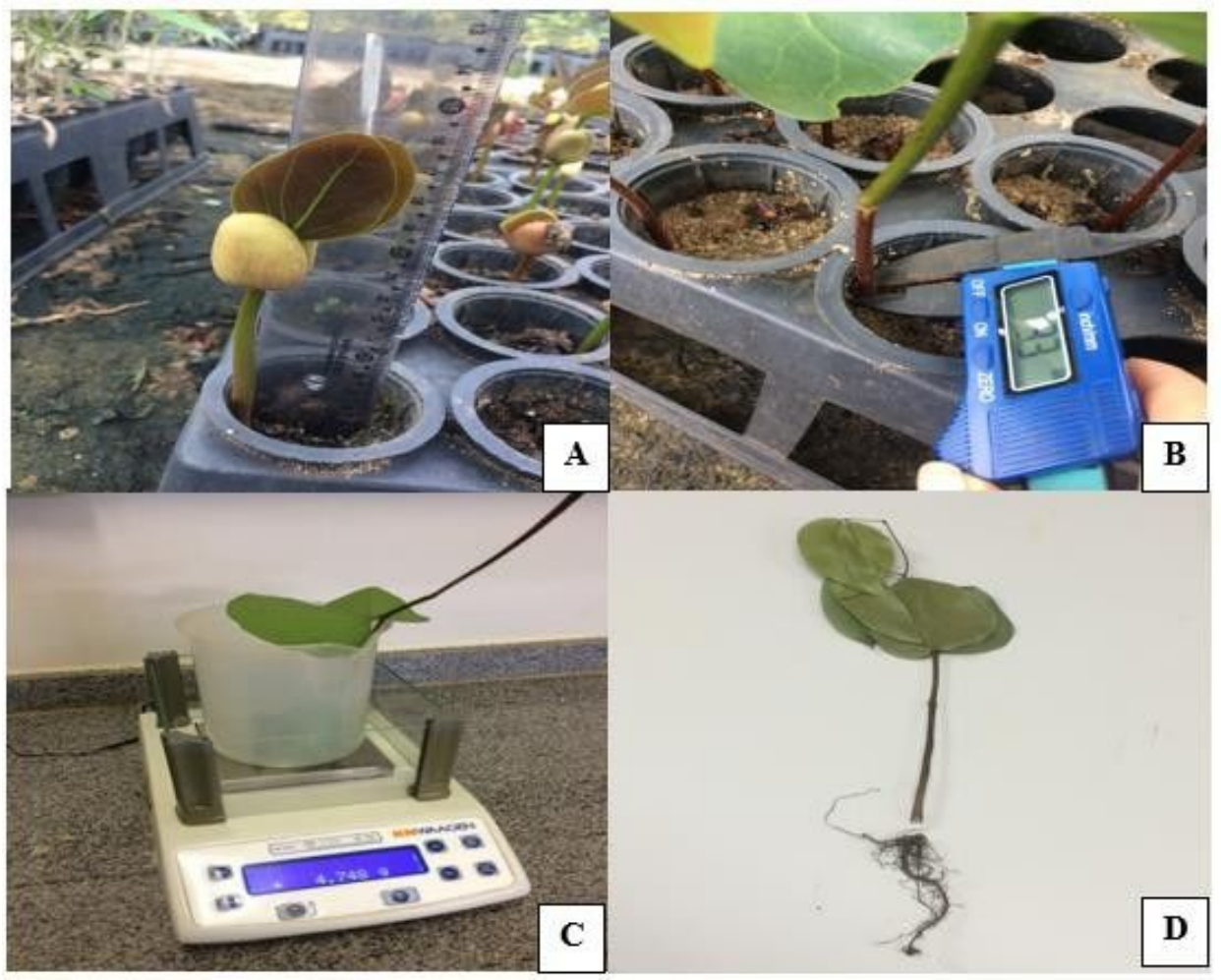

Fonte : Christiane Amaral (2020)

Os resultados obtidos foram submetidos à análise de variância e as médias comparadas pelo teste de Tukey a 5\% de probabilidade (GOMES, 1987) ao nível de significância (alfa) $5 \%$ ou 0,05 , partindo da hipótese que todos os tratamentos 
apresentam medias semelhantes entre si, ou seja, as medias são iguais (hipótese nula) ou que há pelo menos um tratamento que apresentam media diferente dos demais tratamentos (hipótese alternativa).

\section{RESULTADOS E DISCUSSÃO}

No teste de germinação aos nove dias foi possível identificar protrusão radicular, e percentual germinativo de $91 \%$ após 19 dias (Figura 4).

FIGURA 4. Protrusão radicular de sementes de jatobá-damata (Hymenaea courbaril L.), em laboratório. Fonte:

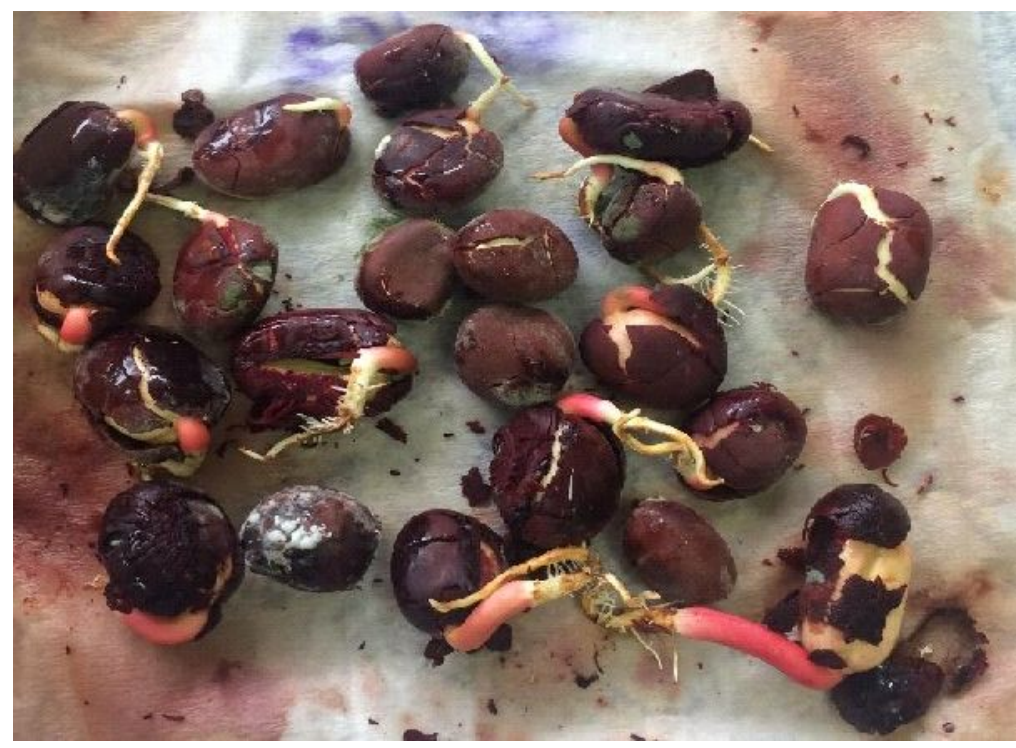

Fonte; Christiane Amaral (2020)

No viveiro sob telado, a emergência das sementes iniciou-se aos 10 dias após a semeadura e se prolongou até aos 23 dias, e o percentual germinativo foi de $83 \%, 81 \%$ e $90 \%$, respectivamente, nos tratamentos T1 (100\% composto orgânico de casca de batata), T2 (50\% composto orgânico de casca de batata $+50 \%$ areia) e T3 (100\% areia).

Cabral et al., (2015), observaram, em trabalho com o Jatobá, que o tratamento com escarificação com lixa seguido de embebição por quatro horas em água se mostrou eficiente com porcentagem de germinação acima de $90 \%$, sendo esta porcentagem considerada alta, de acordo com a Embrapa (2013).

Assim, verificou-se que o jatobá-da-mata no presente estudo apresentou uma alta taxa de germinação, após as sementes passarem por processo de quebra de dormência com escarificação mecânica. Segundo Ramalho et al., (2019), as sementes de muitas espécies florestais apresentam restrições à passagem de água e do oxigênio impostas pelo tegumento, neste caso, a semente apresenta dormência tegumentar porque os tecidos que a envolvem exercem um impedimento que precisa ser superado para que a germinação aconteça.

A avaliação das váriáveis iniciou-se com a altura $(H)$, segundo o teste de Tukey a $5 \%$ de probabilidade, não apresentou diferença estatística significativa entre os ENCICLOPÉDIA BIOSFERA, Centro Científico Conhecer - Jandaia-GO, v.17 n.34; p. 529 2020 
tratamentos nas diferentes avaliações (Figura 5). Medeiros et al. (2017) avaliaram o crescimento de mudas de Moringa oleifera Lam., produzidas em composto orgânico à base de esterco bovino e restos de culturas como feijão, capim, citronela, oleáceas, folhas de jaqueiras, folhas de oliveiras e compararam os resultados com os obtidos em solo. Evidenciou-se que o composto orgânico apresentou mudas com melhor crescimento em altura de plantas, diâmetro caulinar, número de folhas e comprimento radicular.

FIGURA 5. Altura média (cm) de mudas de jatobá-da-mata (Hymenaea courbaril L.) nos diferentes tratamentos e suas repetições.

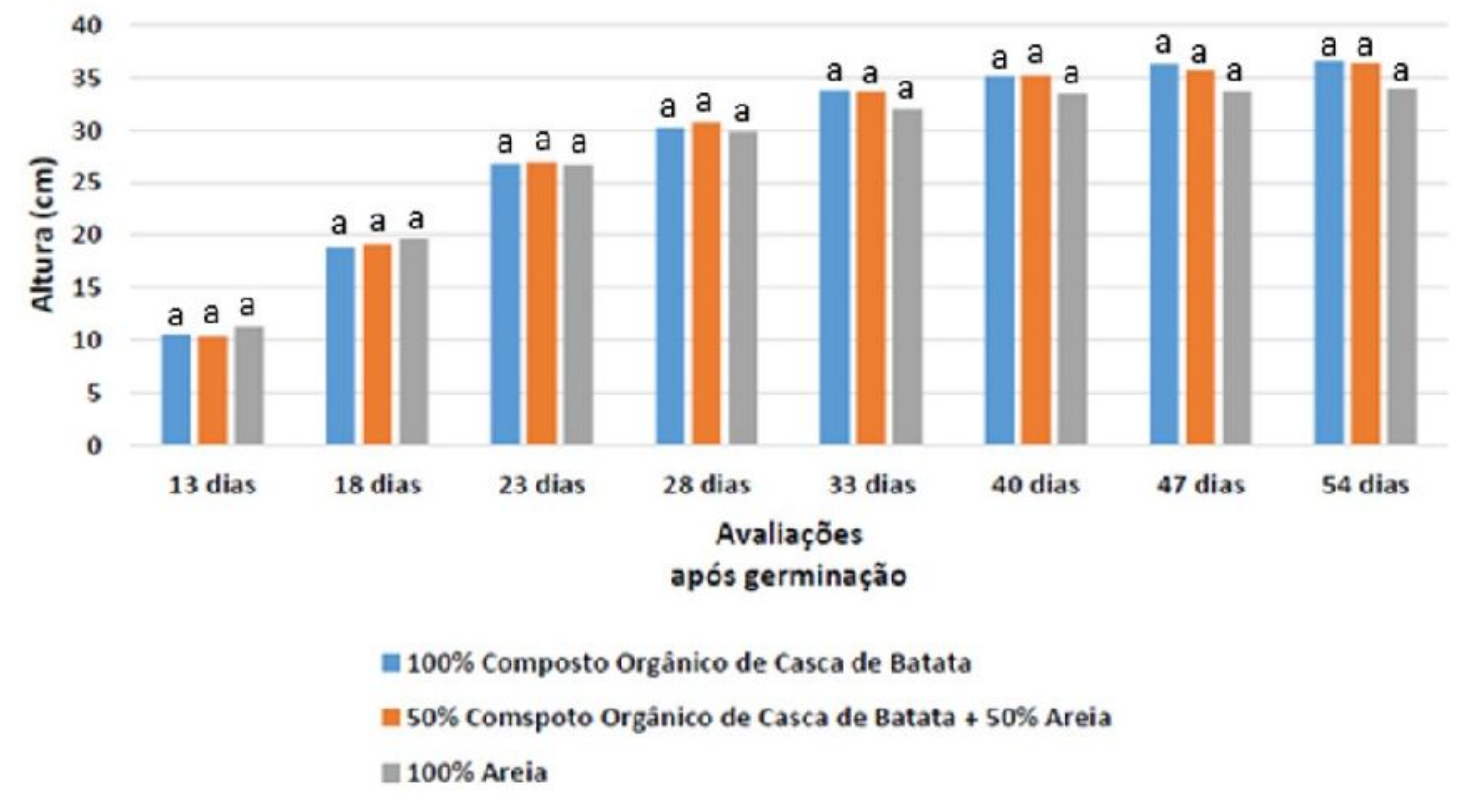

A variável diâmetro do coleto (DC) das mudas, segundo o teste de Tukey a $5 \%$ de probabilidade, apresentou diferença estatística significativa somente na terceira avaliação, aos 23 dias após a germinação das sementes, com menor média no tratamento de composto de casca de batata, porém essa diferença não se manteve, sendo considerado que ao final de todas as análises, os tratamentos não diferiram entre si, apresentando medias semelhantes (Figura 6).

Embora não tenha apresentado diferença entre os substratos para a produção de Jatobá, Silva Junior (2016), avaliou o uso de composto de casca de batata para produção de mudas de Khaya ivorensis A. chev. No estudo foi evidenciada a alta eficácia do composto orgânico na produção de mudas de mogno africano. Valendo ressaltar que as maiores médias finais de diâmetro do coleto se concentraram no tratamento (composto orgânico (100\%)), chegando a apresentar médias $50 \%$ maiores que as verificadas nos tratamentos que não tinham composto orgânico em sua composição. 
FIGURA 6. Diâmetro do coleto $(\mathrm{mm})$ de mudas de jatobá-da-mata (Hymenaea courbaril L.) nos diferentes tratamentos e repetições.

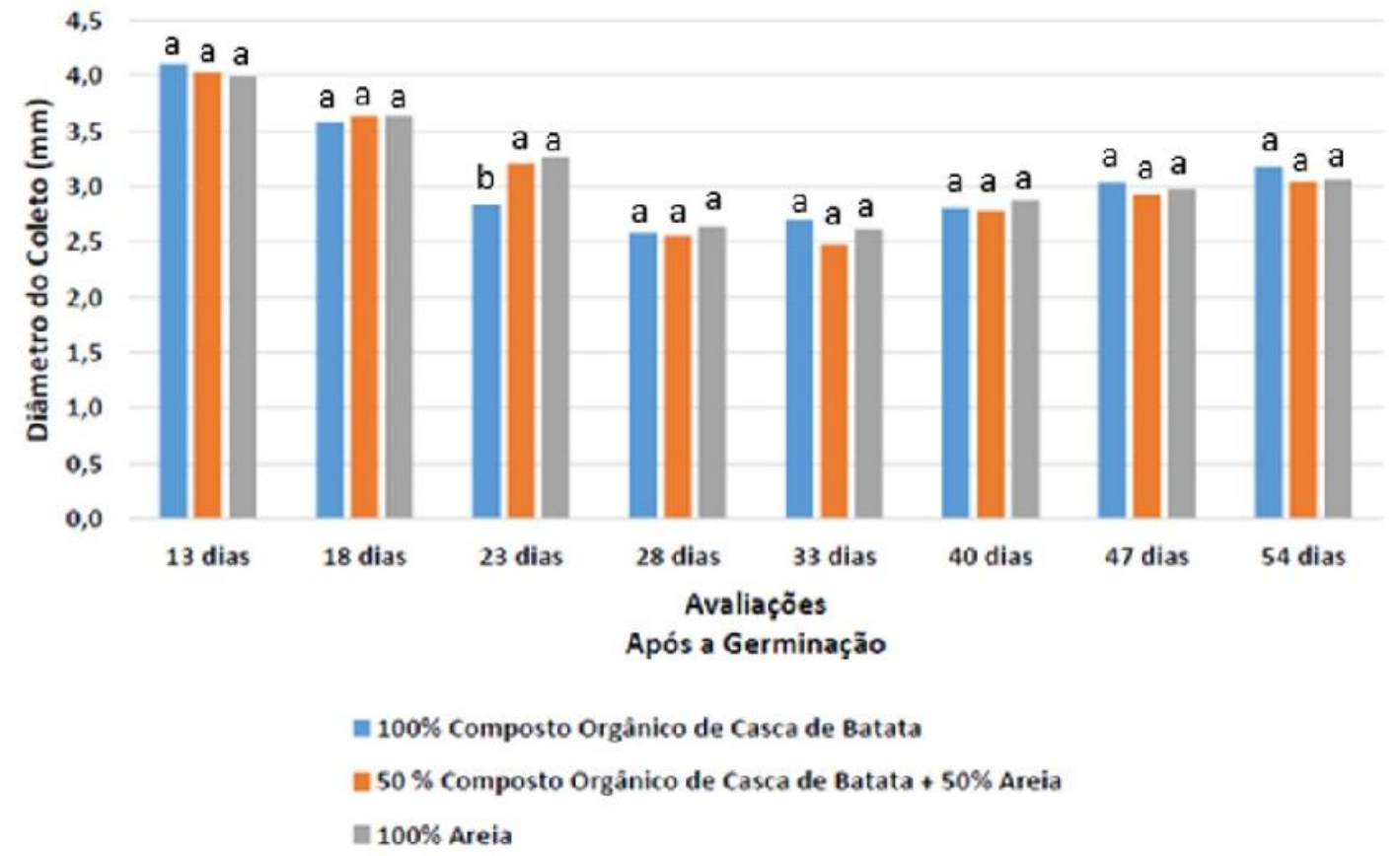

As variáveis: peso verde da parte aérea (PVPA) (Figura 7) e peso seco da parte aérea (PSPA) (Figura 8) para o teste de Tukey a $5 \%$ de probabilidade, não apresentaram diferença estatística significativa entre nenhuma das avaliações ao final da análise, apresentando médias semelhantes entre os tratamentos.

FIGURA 7. Peso verde da parte aérea $(\mathrm{g})$ de mudas de jatobá-da-mata (Hymenaea courbaril L.) nos diferentes tratamentos e repetições

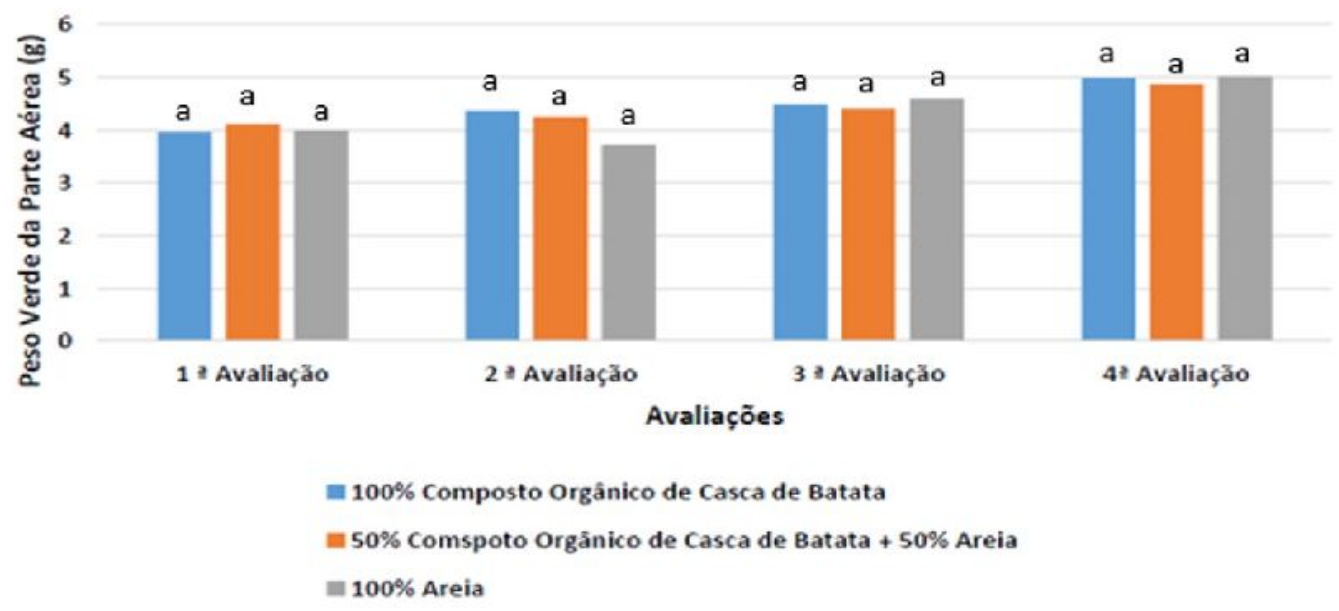


FIGURA 8. Peso seco da parte aérea $(\mathrm{g})$ de mudas de jatobá-da-mata (Hymenaea courbaril L.) nos diferentes tratamentos e repetições.

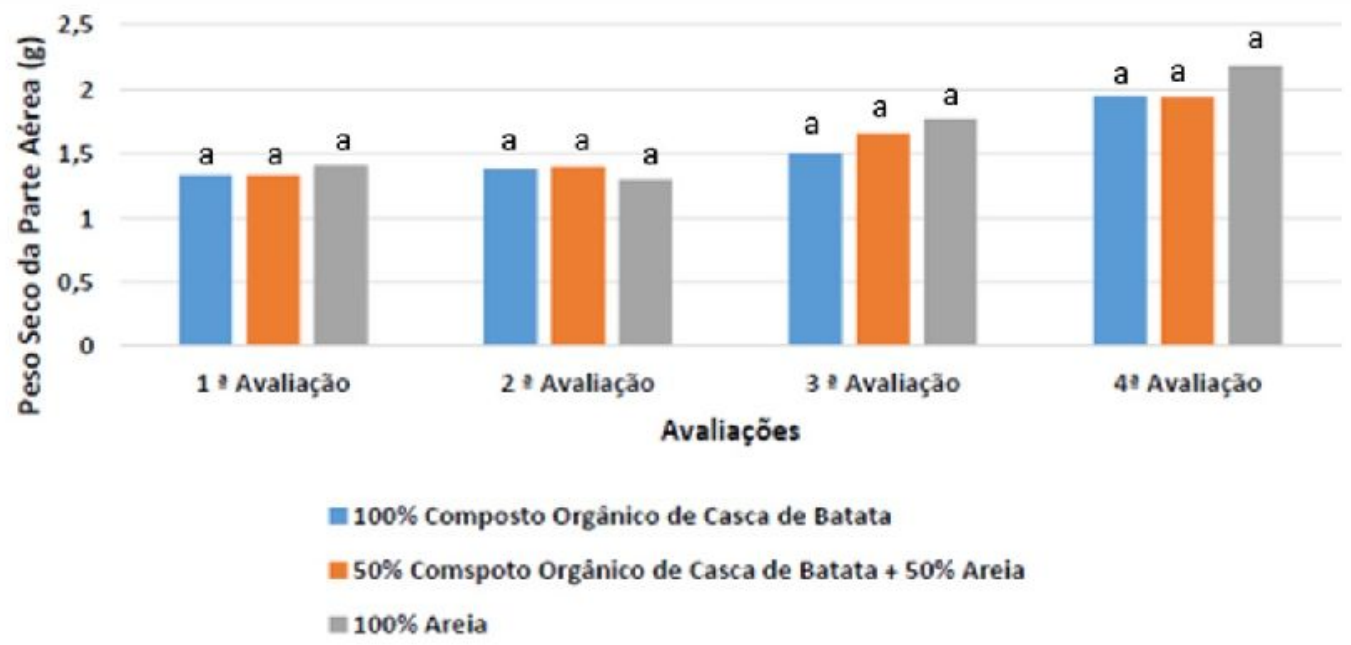

As variáveis: peso verde do sistema radicular (PVSR) (Figura 9) e peso seco do sistema radicular (PSSR) (Figura 10) para o teste de Tukey a 5\% de probabilidade, não apresentaram diferença estatística significativa entre nenhuma das avaliações ao final da análise, apresentando médias semelhantes entre os tratamentos.

FIGURA 9. Peso verde do sistema radicular $(\mathrm{g})$ de mudas de jatobá-da-mata (Hymenaea courbaril L.) nos diferentes tratamentos e repetições.

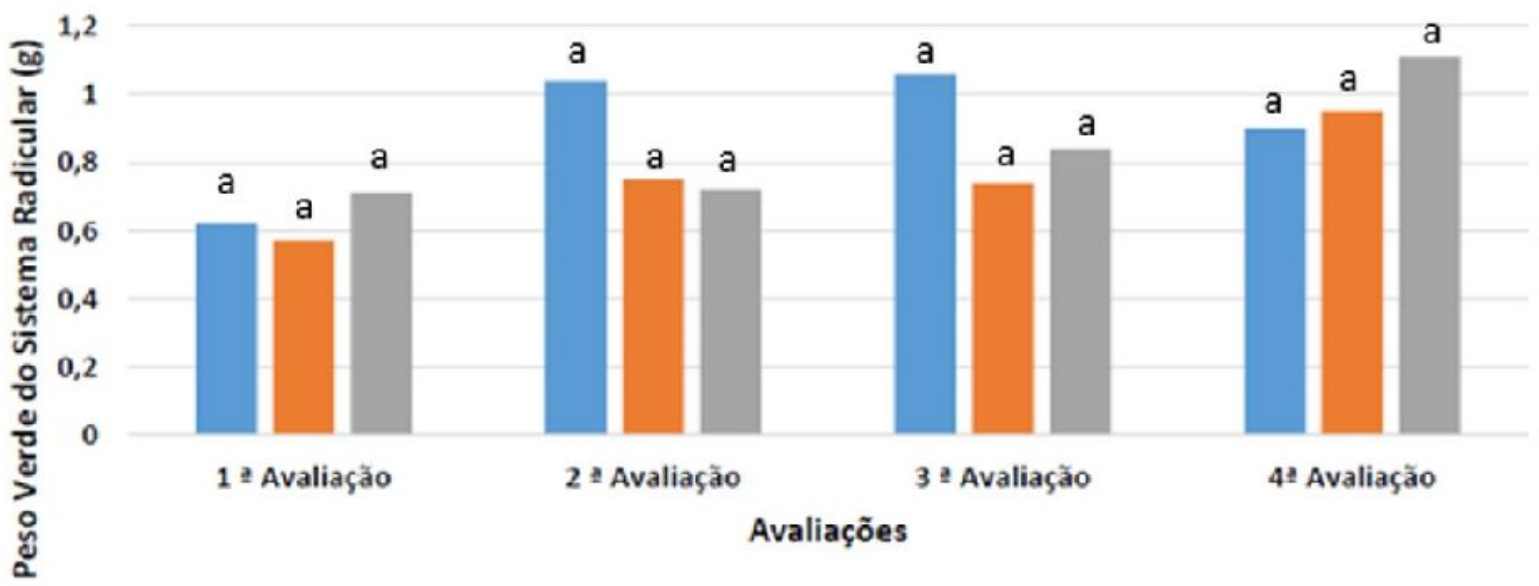

E $100 \%$ Composto Orgânico de Casca de Batata

— $50 \%$ Comspoto Orgânico de Casca de Batata $+50 \%$ Areia

$100 \%$ Areia 
FIGURA 10. Peso seco do sistema radicular $(\mathrm{g})$ de mudas de jatobá-da-mata (Hymenaea courbaril L.) nos diferentes tratamentos e repetições.

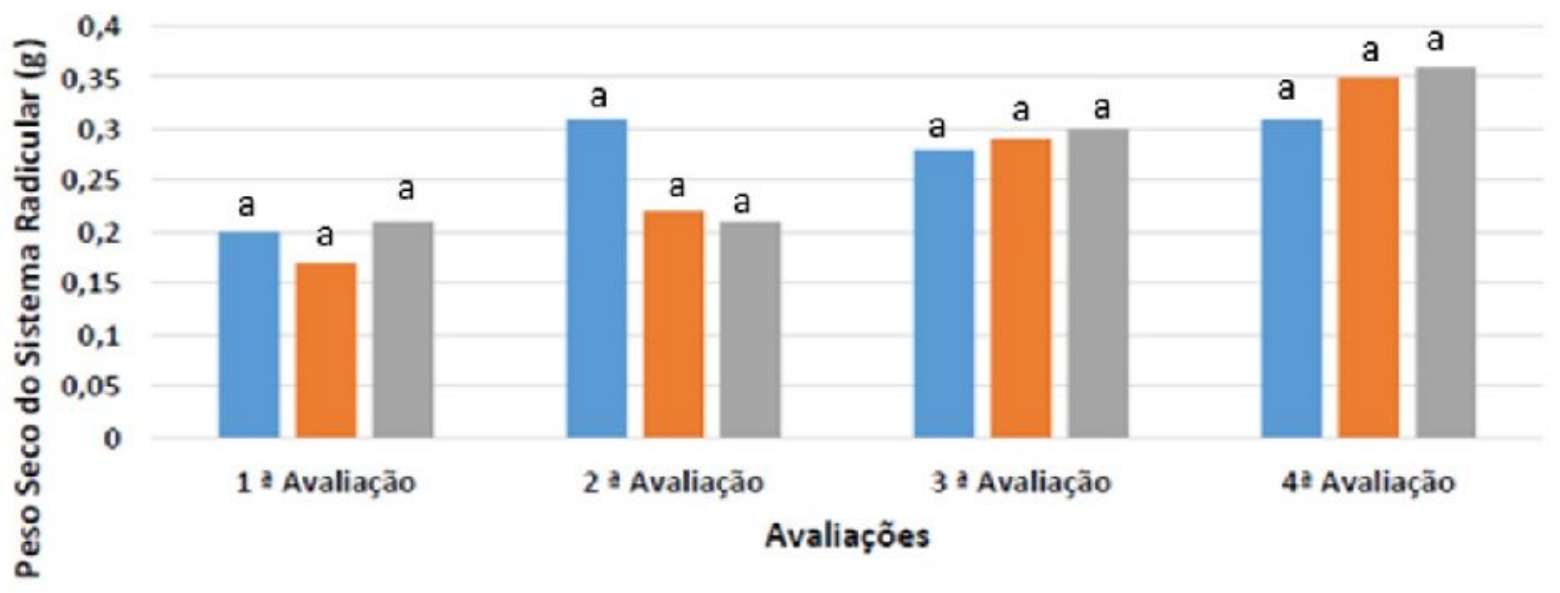

Quando analisadas as variáveis no período de avaliação, as comparações entre tratamentos não apresentaram diferença significativa em nenhuma época de análise. Assim, pode-se optar pelo substrato que onera menos em custo (composto orgânico de casca de batata), por ser proveniente de doação, atribuindo menor custo de produção das mudas e sendo uma alternativa viável para resolver o problema da disposição final desse resíduo, eliminando um agente poluidor no meio ambiente.

O produtor de mudas deve se atentar então, se na região onde está inserido, há disponível a quantidade de resíduos orgânicos com potencial de reutilização que atenda a demanda de produção de mudas florestais no viveiro, bem como, verificar quais espécies se desenvolvem bem em substratos a base de compostos orgânicos através de testes no próprio viveiro, sendo o substrato a base de composto orgânico de casca de batata viável para a produção de mudas de jatobá-da-mata (Hymenaea courbaril L.), verificado no presente estudo.

Diante dos resultados de todas as avaliações, em que de modo geral nenhuma das variáveis apresentaram diferenças significativas entre os tratamentos, cabe inferir sobre a espécie em estudo. O jatobá-da-mata é considerada uma das espécies denominadas vicariantes, as quais estão presentes tanto nas matas quanto nos cerrados (DECHOUM, 2004). Segundo Carvalho (2007), o jatobá-da-mata (Hymenaea courbaril L.) pode ocorrer tanto em solos de alta como de média fertilidade (COSTA et al., 2011). Outra peculiaridade do jatobá são as baixas exigências nutricionais e hídricas requeridas pela espécie em ambientes naturais, sendo observada a presença em terrenos que apresentam solos distróficos e bem drenados (LEE; LANGENHEIM, 1975). 
Outro ponto relevante é devido ao jatobá-da-mata ser uma espécie que possui hábitos de crescimento lento, se enquadra como espécie climácica na sucessão ecológica (LOZENZI, 1998). Conforme Chapin III (1980), espécies de crescimento lento são características de solos de baixa fertilidade, e quando comparadas às espécies de solos mais férteis, em geral, exibem uma baixa taxa de absorção iônica por planta e um pequeno incremento na taxa de absorção em resposta ao aumento de concentrações externas de nutrientes. O jatobá-da-mata (Hymenaea courbaril L.) em relatos, recebe afirmações sobre sua vasta distribuição geográfica e habilidade de se desenvolver bem em ambientes com diferentes características edafoclimáticas, assim, vem se destacando no cenário científico nacional especialmente por apresentar estratégias adaptativas interessantes para diversas áreas, como: a fisiologia e bioquímica vegetal, a biotecnologia e o melhoramento genético de plantas (CARVALHO, 1994; PAIVA, 2003).

Assim, vale ressaltar que, de acordo com o grupo sucessional a que a espécie pertence; as baixas exigências nutricionais, concordando com Clarkson, (1985), plantas de crescimento lento, são menos sensíveis às mudanças no ambiente nutricional, refletindo em uma taxa menos flexível de crescimento; e o bom desenvolvimento em ambientes com diferentes características edafoclimáticas. Os valores no desenvolvimento do jatobá-da-mata, nos diferentes tratamentos, podem apresentar maior semelhança, principalmente por ser uma espécie de crescimento lento, que se enquadra como espécie climácica na sucessão ecológica. Sendo essas características uma possível explicação da similaridade nos valores obtidos para o crescimento em altura, diâmetro do coleto, massa verde da parte aérea, massa verde do sistema radicular, massa seca da parte aérea e massa seca do sistema radicular.

Neste caso, a hipótese nula é aceita, em que todos os tratamentos apresentam médias semelhantes entre si, ou seja, as médias são iguais. Assim, devido ao jatobáda-mata ter baixa exigência nutricional, o uso de um dos tratamentos, em específico, não oferece vantagem, entretanto o composto orgânico de casca de batata é o mais indicado, pois é fruto de doação, onerando menos o processo de produção de mudas florestais, além de dar utilização viável a um resíduo industrial, sendo a geração de resíduos um dos fatores que mais contribui para a degradação do meio ambiente, além de tornar-se um problema sanitário, ambiental e social (HOORNWEG; BHADA-TATA, 2012).

Desta forma, a utilização do composto orgânico de casca de batata é a mais viável no ponto de vista econômico e ambiental, pois atribui redução dos gastos de transporte e destinação do lixo orgânico produzido pela empresa, constituindo-se uma forma correta de tratamento e destino com baixo custo agregado (SANTOS, 2011). E também pode ser utilizada como instrumento de educação ambiental, despertando a consciência ecológica. Portanto, cabe ressaltar a importância da conscientização ambiental voltada para os processos de produção e meios sustentáveis agrícolas.

\section{CONCLUSÕES}

- $\quad$ O uso de um dos tratamentos, em específico, não oferece vantagem ao produtor de mudas, devendo este optar pelo composto de casca de batata, doado pela indústria alimentícia, que onera menos o produtor. 
- O uso do composto orgânico de casca de batata é viável tecnicamente e economicamente para a produção de mudas de jatobá-da-mata (Hymenaea courbaril L.), aliando benefícios monetários e melhoria na qualidade ambiental.

\section{REFERÊNCIAS}

BARBOSA, N. P.; CONCEIÇÃO, E. C. DA. Aproveitamento de Resíduos Industriais de Alimentos com Potencial Aplicação em Cosméticos Naturais. Revista Processos Químicos, v. 10, n. 20, p. 127-131, 1 jul. 2016. Disponível em: http://ojs.rpqsenai.org.br/index.php/rpq_n1/article/view/357/346. DOI https://doi.org/10.19142/rpq.v10i20.357.

BARRETO, A.; LUIZ, A.; CORREIA, B.; BEQUIMA M, I.; TRINDADE, M., SANTOS, R. Resíduos sólidos: uma revisão bibliográfica. Acesso em: 12 de março de 2017.

BETTIOL O.; CAMARGO E. D. Impacto ambiental do uso agrícola do lodo de esgoto. Jaguariúna, SP: Embrapa Meio Ambiente, 2000. p. 312. Disponível em: https://ainfo.cnptia.embrapa.br/digital/bitstream/item/130046/1/2006PL-039.pdf. Acesso em: 17 nov. 2016.

CABRAL, E. M. S.; CASTILHO, M. M.; PAGLIARINI, M. K. Germinação de Sementes e Desenvolvimento de Mudas de Jatobá (Hymeneae courbaril L. Var. Stilbocarpa). Revista Eletrônica Thesis, São Paulo, ano XI, n. 23, p.16-28, $1^{\circ}$ semestre, 2015. Disponível em: http://www.cantareira.br/thesis2/ed_23/materia2.pdf.

COSTA, W. S.; SOUZA, A. L.; SOUZA, P. B. Jatobá - Hymenaea courbaril L.: ecologia, manejo, silvicultura e tecnologia de espécies nativas da Mata Atlântica. Viçosa: Polo de Excelência em Florestas, 2011. 21 p. Acesso em: 20 dez. 2015.

HOORNWEG, D.; BHADA-TATA, P. What a waste: a global review of solid waste management. Washington: Urban Development \& Local Government Unit, World Bank v. 15, p. $98,2012$.

Instituto Nacional De Meteorologia. 1961-1990. Disponível em: www.inmet.gov.br/portal/index.php?r=clima/normaisclimatologicas, Acesso em: 28 de junho de 2017.

KRAEMER, M. E. P. Passivo Ambiental. Disponível em: http://amda.org.br/imgs/up/Artigo_21.pdf acesso em 15 de fevereiro de 2017.

LORENZI, H. Árvores brasileiras: manual de identificação e cultivo de plantas arbóreas nativas do Brasil. 7.ed. Instituto Plantarum, Nova Odessa, v.1, p. 384, 2016.

MARTINS, S. V. Recuperação de áreas degradadas: ações em áreas de preservação permanente, voçorocas, taludes rodoviários e de mineração. 3. ed. Viçosa: Aprenda fácil, 2013, v. 1.264 p. 
MEdeiRos, R. L. S.; CAVAlCANTE, A. G.; CAVAlCANTE, A. C. P.; SOUZA, V. C. Crescimento e qualidade de mudas de Moringa oleífera Lam em diferentes proporções de composto orgânico. Revista Ifes Ciência, Espirito Santo, v. 3, no 1, 2017. Disponível em: https://ojs2.ifes.edu.br/index.php/ric/article/view/777/487.

RAMALHO, C. I.; CAMILO, F. L.; PARANAGUÁ, L. A. M. N.; GOMES, G. L. S. Avaliação de diferentes tratamentos pré-germinativos para sementes de Jatobá do Cerrado (Hymenaea stigonocarpa L.). Revista Brasileira de Meio Ambiente, Piauí, v. 7, n. 2, p. 2-9, fev. 2019. Disponível em: https://revistabrasileirademeioambiente.com/index.php/RVBMA/article/view/260/182. DOI https://doi.org/10.5281/zenodo.3524805. Acesso em: 7 nov. 2020.

SILVA, L. L.; BECKER, Q. M. C.; OTALAKOSKI, J.; MENEGHELLO, G. E. Produção de mudas de Hymenaea courbaril L. em diferentes substratos. Revista Científica Rural, Bagé - RS, v. 21, n. 2, p. 226-238, 20 nov. 2018. Disponível em: http://revista.urcamp.tche.br/index.php/RCR/article/view/2673. https://doi.org/10.30945/rcr-v21i2.2673.

VALLE, C. E. Qualidade Ambiental: ISO 14000. Pág. 27-28. Washington: Urban Development \& Local Government Unit, World Bank v. 15, p. 98, 2012.

ZARO, M. Desperdício de Alimentos: Velhos hábitos, novos desafios. 2. ed. atual. Caxias do Sul, RS: EDUCS, 2018. 167 p. ISBN 978-85-7061-917-4. E-book. 